\title{
Effect of Turbulence Flow on Pressure Drop in a Single Phase Vertical Pipe
}

\author{
Adekomaya A. Olufemi*,a, Adewuyi Ademola and Olafuyi Olalekan ${ }^{\mathrm{b}}$ \\ ${ }^{a}$ University of Lagos, Department of Petroleum and Gas Engineering,Akoka,Lagos,Nigeria; ${ }^{b}$ University of \\ Benin,Department of Petroleum |Engineering,Benin City,Edo State,Nigeria
}

\begin{abstract}
The published work literature on pressure drop in a single phase flow is reviewed. While many papers have been published on the prediction of bottom-hole pressure in single phase vertical gas wells; there are not many studies that show the effects of friction on this flow of interest. A model has thus far been derived from first principle as an improvement over Sukkar and Cornell's approach of calculating bottom-hole pressure by the introduction of friction factor in the turbulent region. Suggested friction factor under varying conditions are explicitly discussed.Finally, two models are compared, one considered the friction effect while the other assumed a non friction factor.
\end{abstract}

Keywords: Single phase, turbulence flow, pressure drop, friction factor, vertical pipe, temperature.

\section{INTRODUCTION}

In field development, the engineer is concerned with fluid flow in the reservoir and wellbore.Single phase flow occurs in the wellbore of mostly dry gas wells. The engineer is therefore interested in simulating the single phase flow to obtain information about the reservoir and the production characteristics of gas wells. The surveillance of gas wells is of increasing interest in the petroleum industry as the economic importance of natural gas continues to grow.The ability of a gas reservoir to produce for a given set of conditions depends on the flowing bottom-hole pressure, $\mathrm{P}_{\mathrm{wf}}$ Reservoir properties control the inflow performance of wells, or the potential of gas production rate from the well.However, the achievable production rate from the well is determined by well head pressure and the flow performance of production string, (tubing,casing,or both).The flow performance of production strings depends on geometries of the production string and the properties of fluid being produced.The fluids in gas wells are mainly gases with small fractions of water,condensate, and sand from the productive zones.

Single phase vertical flow has been studied by quite some few investigators in the past. The equations that describe such flow are the continuity equation, momentum equation and energy equations. These are then used to express the total pressure drop up the wellbore in terms of its elevation, frictional and acceleration components. In this research, extensive literature of the petroleum industry has been drawn upon while many papers have been published on the prediction of flowing bottom-hole pressure in single phase vertical wells; there are not many studies that show the effect of turbulence on the flow of interest. Nikuradse [1] had

*Address correspondence to this author at the University of Lagos, Department of Petroleum and Gas Engineering,Akoka,Lagos,Nigeria;

Tel: +2348027844810; E-mail: femadec12@yahoo.com verified the Prandtl's mixing length theory and proposed the following universal resistance equation for fully developed turbulent flow in smooth pipe:

$$
\frac{1}{\sqrt{f}}=2 \log (\operatorname{Re} \sqrt{f})-0.8
$$

In case of rough pipe flow, the viscous sub layer thickness is very small when compared to roughness height and thus the flow is dominated by the roughness of the pipe wall and $\mathrm{f}$ is a function of $\frac{\varepsilon}{D}$ only and is independent of Re.The following form of the equation is first derived by Schlichting [2] and later supported by Nikuradse's experiments [1]:

$$
\frac{1}{\sqrt{f}}=2 \log \left(\frac{D}{\varepsilon}\right)+1.74
$$

For transition regime in which the friction factor varies with both $\operatorname{Re}$ and $\frac{\varepsilon}{D}$, the equation universally adopted is due Colebrook and White [3] proposed the following equation:

$$
\frac{1}{\sqrt{f}}=-2 \log \left(\frac{\varepsilon / D}{3.7065}\right)+\frac{2.5226}{\operatorname{Re} \sqrt{f}}
$$

Zagarola [4] has indicated that the Prandtl's law of flow in smooth pipes was not accurate for high Reynolds numbers and the Colebrook and White correlation [3] (which was based on the Prandtl's law of flow) is not accurate at high Reynold's numbers.Moreover, several reseachers have found that Colebrook and White equation [3] is inadequate for pipes smaller than $2.5 \mathrm{~mm}$.

Chen [5] proposed equation for friction factor covering all the ranges of Re and $\frac{\varepsilon}{D}$ : 
$\frac{1}{\sqrt{f}}=2 \log \left(\frac{\varepsilon}{3.7065 D}\right)-\log \frac{1}{2.8257}\left(\frac{\varepsilon}{D}\right)^{1.1098}+\frac{5.8506}{\operatorname{Re}^{0.8981}}$

His method of calculating the friction factor is explicit and does not require iteration to solve but it definitely does not apply in the laminar zone and it probably does not apply in the critical zone.

This work focuses on the prediction of pressure drop (difference between the wellhead pressure and the flowing bottom-hole pressure) in a single phase vertical flow under the effect of turbulent frictional flow. It is an attempt to improve on Sukkar and Cornell method of calculating flowing bottom-hole pressure. It basically considers the effect of single phase friction factor in turbulent flow as a function of the internal diameter of the producing tubing.

\section{NATURAL GAS PROPERTIES}

\subsection{Compressibility Factor}

Gas compressibility is also called deviation factor, or zfactor. Its value reflects how much the real gas deviates from the ideal gas at a given pressure and temperature.

Hall and Yarborough [6] presented an accurate correlation to estimate z-factor of natural gas. This correlation is summarized as follows:

$Z=\frac{0.06125 p_{p r} t e^{-1.2(1-t)^{2}}}{y}$

\section{Pseudo-Critical Properties}

Similar to gas apparent molecular weight, the critical properties of a gas can be determined on the basis of the critical properties of compounds in the gas using the kay's mixing rule. Gas pseudo-critical pressure $\left(P_{p c}\right)$ and pseudocritical temperature $\left(T_{p c}\right)$ are, respectively, expressed as

$P_{p c}=\sum_{i=1}^{N c} y_{i} P_{c i}$

$T_{p c}=\sum_{i=1}^{N c} y_{i} T_{c i}$

If the gas composition is not known but gas specific gravity is given, the pseudo-critical pressure and temperature can be determined from various charts or correlations developed based on the charts. One of the accurate correlations is given by Thomas et al. [7].

$P_{p c}=709.604-58.718 \gamma_{g}$

$T_{p c}=170.491+307.344 \gamma_{g}$

Therefore the pseudo-reduced pressure and temperature are calculated as:

$P_{p r}=\frac{P}{P_{p c}}$

and
$T_{p r}=\frac{T}{T_{p c}}$

\section{DERIVATION OF MATHEMATICAL MODEL}

The fluid flow from one arbitrary point to another in a given system has a certain quantity of energy associated with each unit mass of fluid. The energy is of many forms, such as pressure-volume energy, Kinetic energy and potential energy. As fluid enters one point in the system, it carries a certain amount of total energy with it. When the same unit mass of fluid passes point two in the system, it has associated with it that same total energy minus a quantity of energy lost from the system. A quantity of energy is always lost or converted, since a pressure drop always accompanies a real flow process in a constant diameter conduit. Therefore, if losses can be accounted for the total energy at two points in any system can be balanced. Hence, the energy balance can be the basic concept for any fluid flow situation whether it is single or multiphase flow provided all the energy term can be evaluated [8].

The energy balance equation can be written as [9]:

$V d p+\frac{u_{g} d u}{2 \alpha g_{c}}+\frac{g d Z}{g_{c}}+\frac{f u_{g}^{2}}{2 g_{c} D} d L+w_{s}=0$

The second term in equation (1) expresses kinetic energy. This term usually is small and may be neglected and if no mechanical work is done on the gas (compression) or by the gas (expansion through a turbine or engine) the term, $\mathrm{w}_{\mathrm{s}}$ is zero.

Convert the pressure-volume energy from square inch to square feet, the reduced form of the mechanical energy equation may be written as:

$\frac{144}{\rho_{g}} d p+\frac{g d Z}{g_{c}}+\frac{f u_{g}^{2}}{2 g_{c} D} d L=0$

\subsection{Gas Density}

Density of gas at a point in a vertical pipe at pressure and temperature may be obtained from the definition of the gas law as [9]:

$$
\rho_{g}=\frac{P M}{Z R T}=\frac{2.70 \gamma_{g} P}{Z T}
$$

\subsection{Gas Velocity:}

The velocity, u can be expressed in terms of the volume rate and the cross sectional area of the pipe

$$
\begin{aligned}
& U_{g}=\left(\frac{q_{g}}{3600}\right)\left(\frac{T}{T_{b}}\right)\left(\frac{P_{b}}{P}\right)\left(\frac{Z}{1}\right)\left(\frac{4}{\Pi}\right)\left(\frac{1}{D^{2}}\right) \\
& U_{g}{ }^{2}=\frac{0.17237 q_{g}{ }^{2} T^{2} Z^{2}}{P^{2} D^{4}}
\end{aligned}
$$

Substituting equation (3) and (5) into equation (2) above and convert diameter $\mathrm{D}$ (inches) to feet we have, 


$$
\left(\frac{\frac{144 d P}{2.70 \gamma_{g} P}}{Z T}+1+\frac{667 f q_{g}^{2} T^{2} Z^{2}}{P^{2} D^{5}}\right) d L=0
$$

The general vertical flow equation proposed by Sukkar and Cornell is

$$
\int_{3}^{p p r} \frac{Z}{1+B\left(\frac{Z}{P_{p r}}\right)^{2}} d P_{p r}=\frac{0.01875 \gamma_{g} L}{T_{a v g}}
$$

Where $\mathrm{B}$ is assumed to be

$$
B=\frac{667 f q^{2} T_{\text {avg }}^{2}}{D^{5}}
$$

Sukkar and Cornel assumed friction effect to be constant over the lenght of the conduit.

The new model incorporates the friction effect and evaluates how much it contributes to the pressure drop.

Evaluate the friction effect on pipe diameter, $D \leq 4.277$. Using Katz and Lee correlation method [10].

$f=\frac{0.01750}{D^{0.224}}$.

$$
\int_{3}^{P_{p r}} \frac{Z}{1+B\left(\frac{0.01750}{D^{5.224}}\right)\left(\frac{Z}{P_{p r}}\right)^{2}} d P_{p r}=0.01875 \frac{\gamma_{g} L}{T_{a v g}} .
$$

Where $B=667 q_{g}{ }^{2} T_{\text {avg }}{ }^{2}$

\section{Assumptions}

1. Change in kinetic energy is small and may be neglected.

2. Temperature of system is assumed constant at some average value.

3. Flow is turbulent and the tubing wall is nearly smooth.

\section{Model Validation}

The numerical integration was solved by Romberg integration and was converted to a spreadsheet to calculate the bottom hole pressure in other to avoid a rigorous calculation stated by Sukkar and Cornell method.This handy method of calculation was able to calculate the pressure at each point in depth with no influx of errors.

The data of Sukkar and Cornell is listed in Table $\mathbf{1}$ is used to plot (Fig. $\mathbf{1}$ and $\mathbf{2}$ while Table $\mathbf{2}$ is used for Figs. $(\mathbf{3}, \mathbf{4}$ and $\mathbf{5})$.

\section{RESULTS AND DISCUSSION}

Figure 1and 2 compared the obtained Sukkar and Cornel results and the original Sukkar \& Cornell results. The plot for the flowing gas well for $\mathrm{B}=5$ was observed that at lower pseudo reduced pressure the percentage error is about $0.6 \%$ and at higher pseudo reduced pressure the percentage error is
$4 \%$. For flowing gas well for $\mathrm{B}=10$ was observed that at lower pseudo reduced pressure the percentage error is about $0.5 \%$ and at higher pseudo reduced pressure the percentage error is $1.4 \%$.

Table 1. Reservoir Properties Used as Inputs to Calculate the Bottom Hole Pressure

\begin{tabular}{|c|c|}
\hline \multicolumn{2}{|c|}{$\mathbf{z}$-factor Varies } \\
\hline \hline Wellhead Pressure & $1750 \mathrm{psia}$ \\
\hline Temperature & $550^{\circ} \mathrm{R}$ \\
\hline Pseudocritical pressure & 674.13 \\
\hline Pseudocritical temperature & 357.4 \\
\hline Spec gravity & 0.6 \\
\hline Length & $5790 \mathrm{ft}$ \\
\hline B & varies \\
\hline Pseudoreduced pressure & varies \\
\hline Pseudoreduced temperature & 1.5 or 1.6 \\
\hline
\end{tabular}

The next three figures compare the pressure traverse curve for static and flowing gas well for both Sukkar and Cornell Model and the new model.

Fig. (3) revealed the static condition of a gas well. The effect of friction is insignificant and there are no changes in reservoir parameters. The static bottom-hole pressures for the new model and Sukkar and Cornell's method are nearly the same.

Fig. (4) reveals the flowing condition of a vertical gas well where pressure increases with vertical depth for both models. The two slopes representing the two models are seen to deviate progressively from each other as the depth increases. It can be deduced from the plot above that at the lower depth the effect of friction seem to be insignificant due to pressure maintenace but as the depth goes farther to the wellhead and flowing pressure begins to drop,the effect of friction begins to retard the fluid motion.It is also noticed that at $1200 \mathrm{ft}$ there was an obvious deviation between the new model and Sukkar and Cornell method which indicates the influence of friction factor assumed constant by Sukkar and Cornell.The deviation becomes obvious at $6000 \mathrm{ft}$ which shows that the lower the depth the lower the friction and vice versa.Considering the percentage error of the two models from $0 \mathrm{ft}$ to $6000 \mathrm{ft}$, the new model has a percentage error of $13.76134 \%$ while Sukkar and Cornell has $19.13524 \%$ for $\mathrm{B}=5$

Fig. (5) shows the pressure traverse for a flowing vertical gas well $(B=10)$ where the pressure increases with respect to vertical depth for both models. The gradient for Sukkar and Cornell Method is large because friction factor is assumed constant unlike in the proposed model whose gradient is small because of the variation of turbulent friction factor as a function of the tubing internal diameter ( $d=2.259$ in).It is observed from the graph that at $400 \mathrm{ft}$ there was a deviation between the proposed and old model unlike (Fig. 4 in which deviation starts at $1200 \mathrm{ft}$.This can be explained from the 


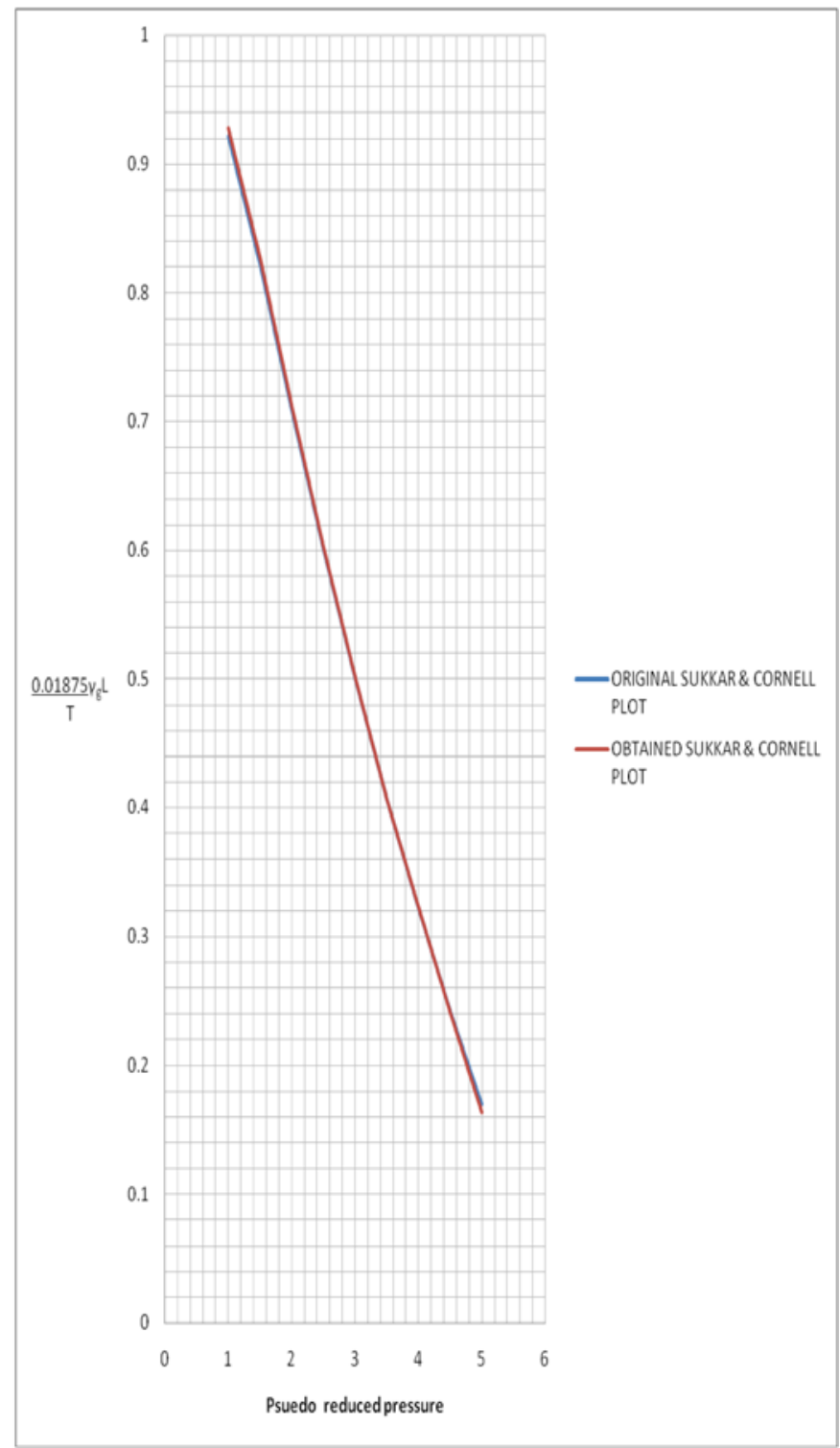

Fig. (1). Plot of $0.01875 \frac{\gamma_{g} L}{T_{a v g}}$ against Pseudo reduced Pressure for $\mathrm{B}=5$.

Table 2. Reservoir Properties Used as Inputs to Calculate the Bottom Hole Pressure

\begin{tabular}{|c|c|}
\hline Wellhead Pressure & $\mathbf{1 7 5 0}$ Psia \\
\hline \hline Temperature & $550^{0} \mathrm{R}$ \\
\hline Pseudocritical pressure & 674.13 \\
\hline Pseudocritical temperature & 357.4 \\
\hline Spec gravity & 0.6 \\
\hline Length & varies \\
\hline B & Varies \\
\hline z-factor & Varies \\
\hline Diameter & 2.259 in \\
\hline Pseudoreduced pressure & Varies \\
\hline Pseudoreduced temperature & 1.5 or 1.6 \\
\hline Depth & varies \\
\hline
\end{tabular}




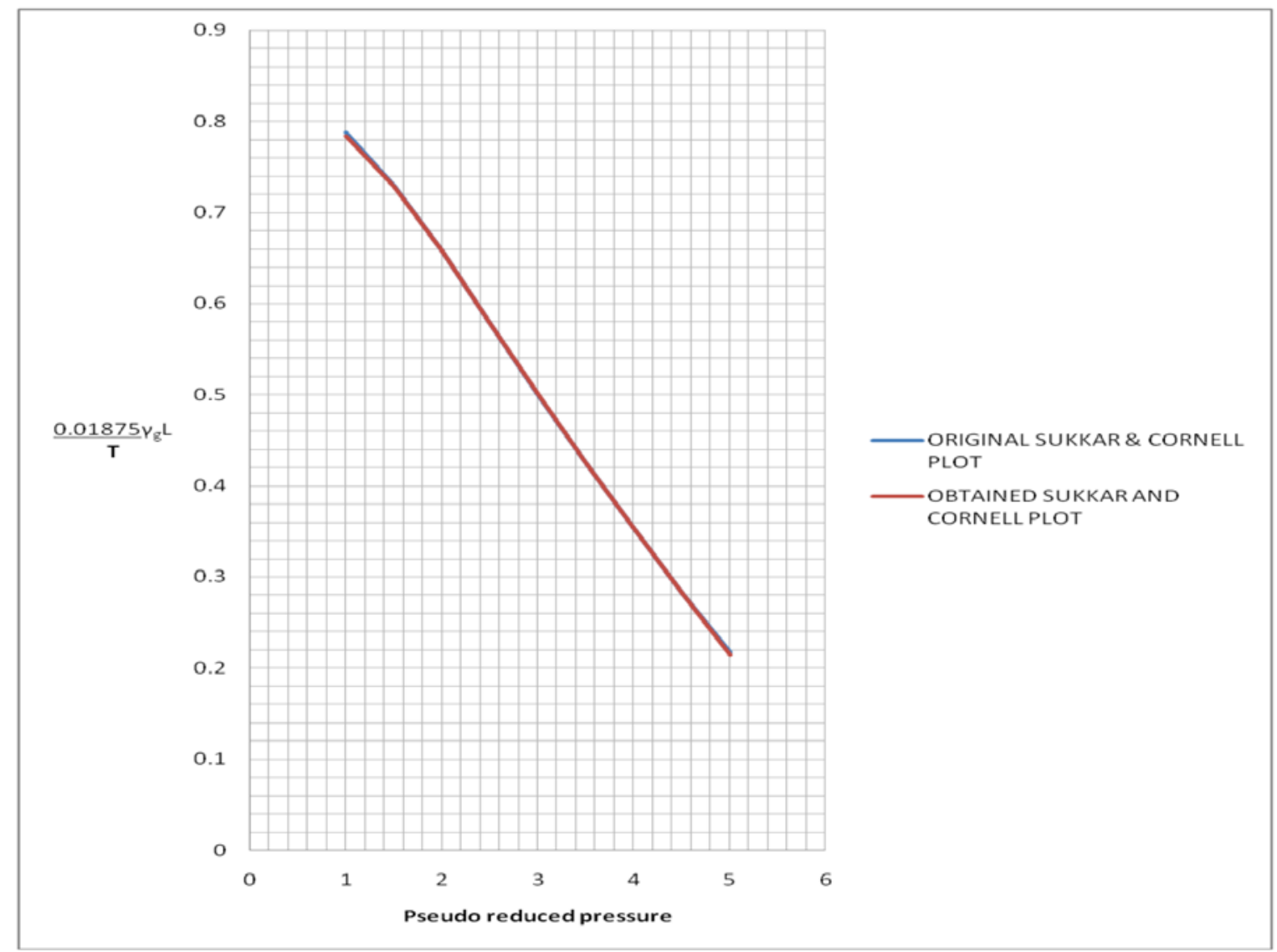

Fig. (2). Plot of $0.01875 \frac{\gamma_{g} L}{T_{a v g}}$ against Pseudo reduced Pressure for $\mathrm{B}=10$.

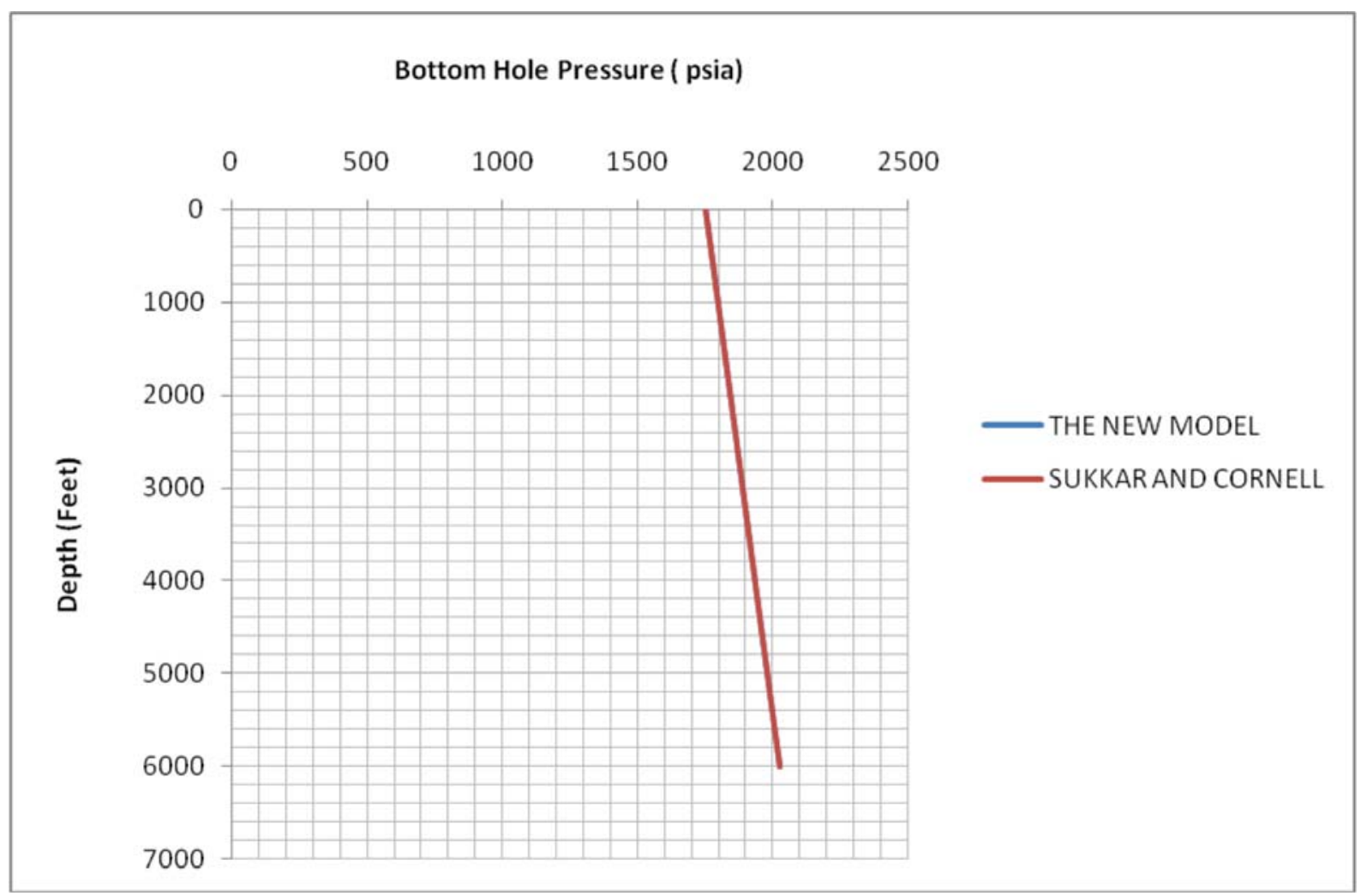

Fig. (3). Pressure traverse curve for a static gas well $(B=0)$. 


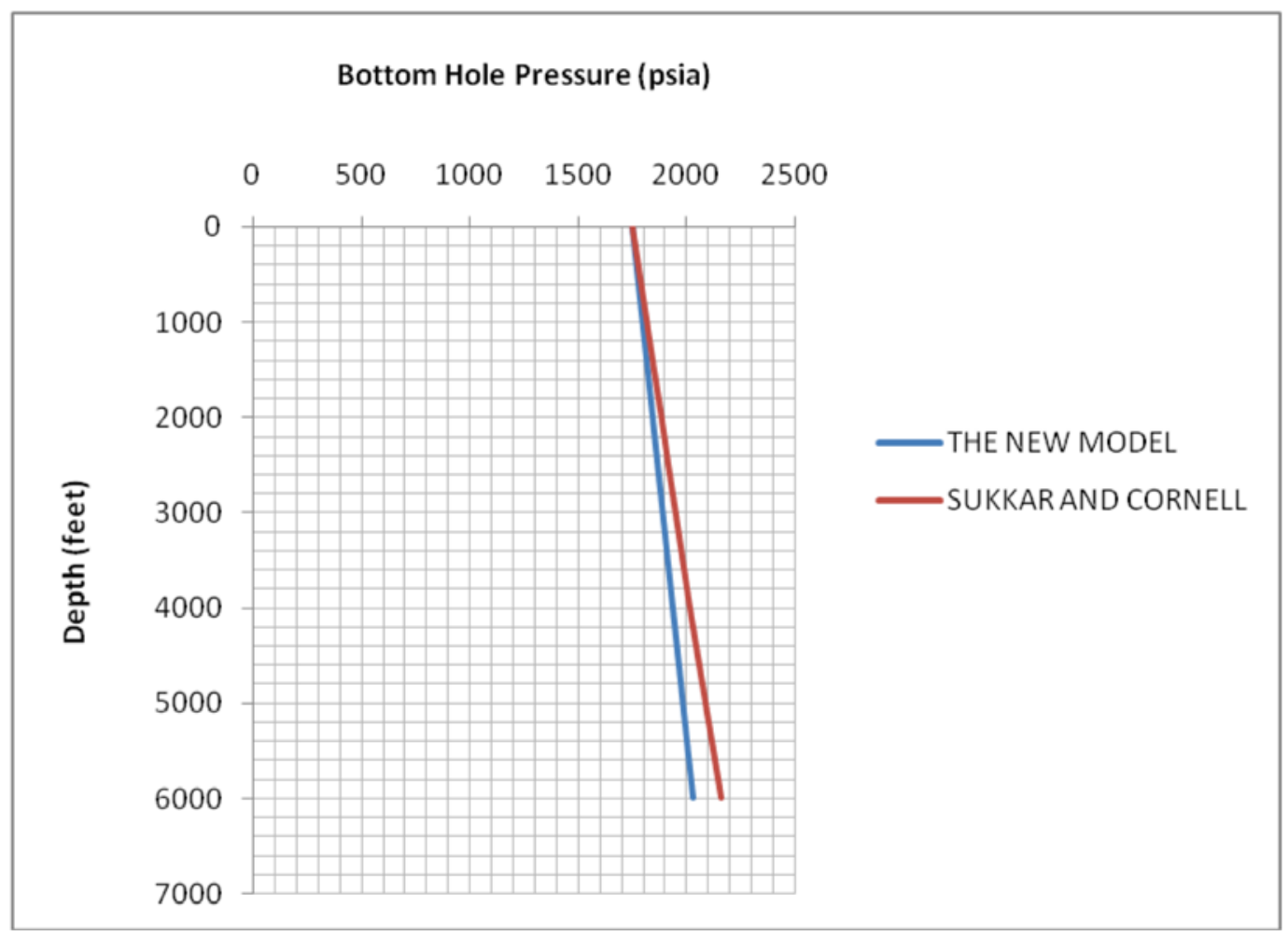

Fig. (4). Pressure traverse curve for a flowing gas well $(B=5)$.

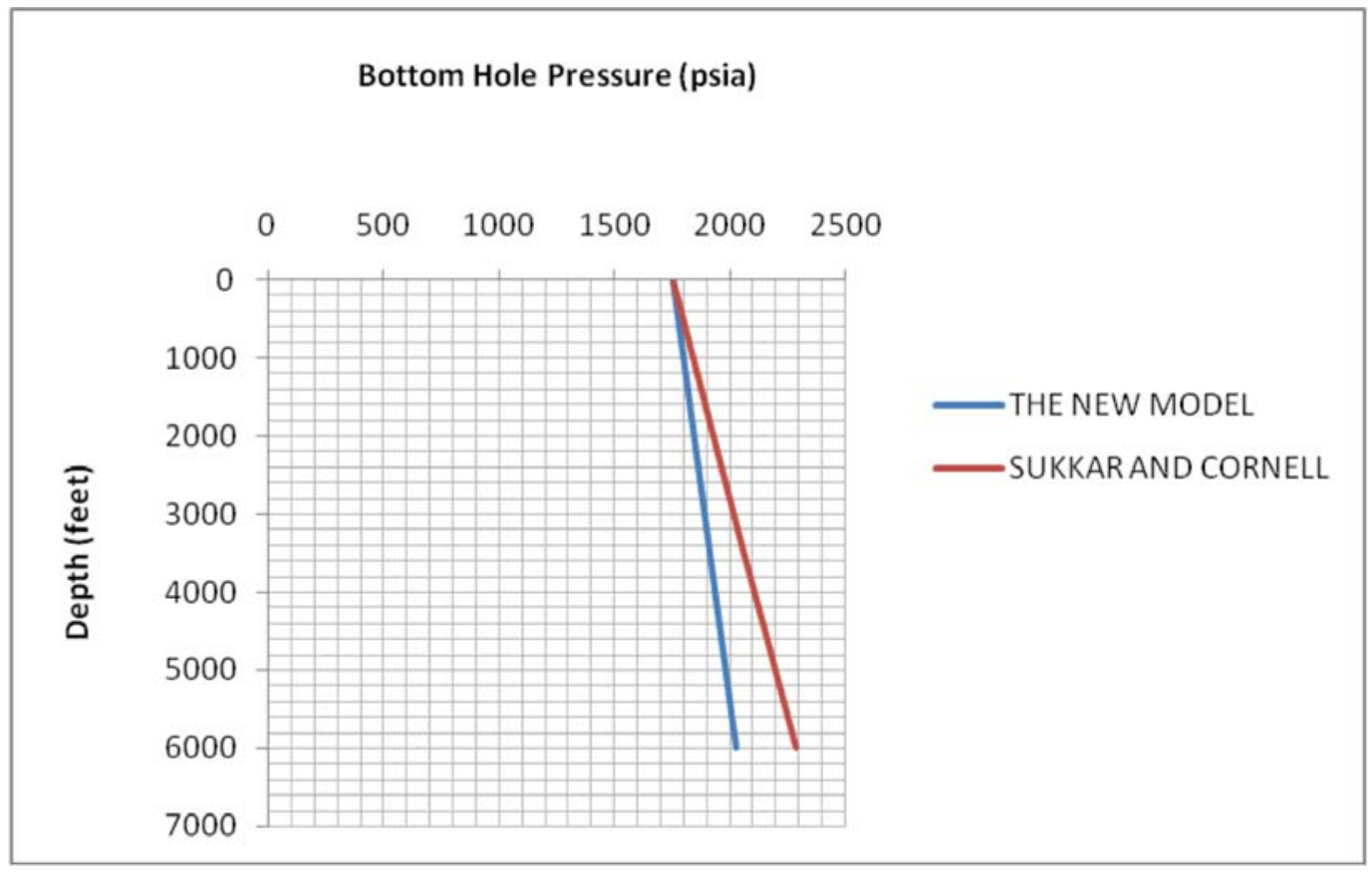

Fig. (5). Pressure traverse curve for a flowing gas well $(B=10)$.

fact that the bigger the $\mathrm{B}$ factor the earlier the deviation. Considering the percentage error of the two models from $0 \mathrm{ft}$ to $6000 \mathrm{ft}$,the new model has a percentage error of $13.757 \%$ while Sukkar and Cornell has $23.35017 \%$ for $\mathrm{B}=10$.

\section{CONCLUSION}

This work has emphasized the effect of friction on pressure drop as a function of pipe diameter.It can be drawn from the results obtained that the variation of friction factor reduces the pressure drop for a given length of production tubing and the B factor which is a function of flowrate plays a significant role in pressure drawdown as the friction effect becomes obvious in larger flowrate at a given pipe lenght.However, the inside wall of a pipe is not smooth.The new model is accurate enough to predict the pressure drop in a nearly smooth pipe.Finally,it is discovered that Sukkar and Cornell method is less accurate in predicting the pressure drop in a pipe length as effect of friction losses which 
represents 5 to $20 \%$ of the total pressure drop in pipe was assumed constant.

\section{Stepwise method of calculating equation (10)}

Step 1: Compute the R.H.S of equation (10)

$0.01875 \frac{\gamma_{g} L}{T_{a v g}}$

Step 2: Calculate the pseudo-reduced temperature and pressure

$P_{p r}=\frac{P}{P_{p c}}$ and $T_{p r}=\frac{T}{T_{p c}}$

Step 3: The value of integral on the L.H.S of equation (10) is obtained by

$$
\int_{a}^{b} f(x) d x \approx h \sum_{i=1}^{n} f\left(a+\frac{2 i-1}{2} h\right)
$$

using different condition of $\mathrm{B}$

Step 4: The value obtained in Step1 is substracted from Step 3

Step 5: The pseudo-reduced pressure corresponding to the integral value in Step 4

under varying condition of $T_{p r}$ and B is selected .

Step 6: Multiply $P_{p r}$ obtained in Step 5 by the Pseudocritical pressure to obtain the required bottom hole pressure.

\section{ACKNOWLEDGEMENTS}

The authors would like to thank the department of Petroleum and Gas Engineering University of Lagos for her support. Prof.A.J Kehinde is appreciated for his fatherly encouragement in the course of this research.

\section{NOMENCLATURE}

$\mathrm{P}=$ pressure, psia

$\mathrm{t}=$ the reciprocal, pseudoreduced temperature $\frac{T_{p c}}{T}$

$\mathrm{y}=$ the reduced density, which can be obtained as the solution of the equation.

$\mathrm{P}_{\mathrm{b}}=$ base pressure

$\mathrm{T}_{\mathrm{b}}=$ base temperature

$\rho=$ density, $\mathrm{lbm} / \mathrm{ft}^{3}$

$B=667 q_{g}^{2} T^{2}$

$\mathrm{e}=$ exponential

$\varepsilon=$ pipes roughness

$\mathrm{P}_{\mathrm{pc}}=$ Pseudo critical pressure

$\mathrm{T}_{\mathrm{pc}}=$ Pseudo critical temperature

$\mathrm{q}_{\mathrm{g}}=$ gas volumetric flowrate, $\mathrm{ft} / \mathrm{sec}$

$\mathrm{P}_{\mathrm{pr}}=$ Pseudo reduced pressure
$\mathrm{R}=$ gas constant, $10.732 \mathrm{ft} 3 \mathrm{psia} / \mathrm{lb}-\mathrm{mol}^{\circ} \mathrm{R}$

$\mathrm{D}=$ inside diameter of the pipe, $\mathrm{ft}$

$\mathrm{T}=$ temperature, ${ }^{\circ} \mathrm{R}$

$\mathrm{f}=$ friction factor

$\mathrm{Z}=$ compressibility factor

$\mathrm{g}=$ acceleration due to gravity, $\mathrm{ft} / \mathrm{sec}^{2}$

$\mathrm{U}_{\mathrm{g}}=$ velocity of the gas, $\mathrm{ft} / \mathrm{sec}$

$\mathrm{g}_{\mathrm{c}}=$ conversion factor, $32.17 \mathrm{lbmft} / \mathrm{lbfs}$.

$\mathrm{V}=$ specific volume of $\mathrm{gas}, \mathrm{ft}^{3} / \mathrm{lbm}$

Re $=$ Reynolds number

$\gamma_{g}=$ gas specific gravity, dimensionless

$\mathrm{w}_{\mathrm{S}}=$ mechanical work done on or by the gas $\left(\mathrm{w}_{\mathrm{s}}=0\right)$

$\mathrm{L}=$ Length of the flow string, ft (for a vertical flow string $\mathrm{L}=\mathrm{Z}$ )

$\frac{u d u}{2 g_{c}}=$ pressure drop due to kinetic energy

$\frac{f u_{g}{ }^{2}}{2 g_{c} D} d l=$ pressure drop due to friction effect

$\mathrm{T}_{\mathrm{pr}}=$ Pseudo reduced temperature

\section{APPENDIX A}

Table A.1. Table of Bottom-Hole Pressure against Depth for Static Well $(B=0)$

\begin{tabular}{|c|c|c|}
\hline DEPTH & $\begin{array}{c}\text { THE NEW MODEL } \\
\text { (WITH EFFECT OF } \\
\text { TURBULENCE) }\end{array}$ & $\begin{array}{c}\text { SUKKAR AND } \\
\text { CORNELL (WITH } \\
\text { NO TURBULENCE) }\end{array}$ \\
\hline \hline 0 & 1749.81 & 1749.81 \\
\hline 500 & 1772.97 & 1772.97 \\
\hline 1000 & 1796.12 & 1796.13 \\
\hline 1500 & 1819.28 & 1819.29 \\
\hline 2000 & 1842.44 & 1842.45 \\
\hline 2500 & 1865.59 & 1865.61 \\
\hline 3000 & 1888.75 & 1888.77 \\
\hline 3500 & 1911.91 & 1911.93 \\
\hline 4000 & 1935.06 & 1935.09 \\
\hline 4500 & 1958.22 & 1958.25 \\
\hline 5000 & 1981.38 & 1981.41 \\
\hline 5500 & 2004.53 & 2004.51 \\
\hline 6000 & 2028.85 & 2028.9 \\
\hline
\end{tabular}


Table A.2. Table of Flowing Bottom-Hole Pressure against

Table 3A. Contd.... Depth for $B=5$

\begin{tabular}{|c|c|c|}
\hline DEPTH & $\begin{array}{c}\text { THE NEW MODEL } \\
\text { (WITH EFFECT OF } \\
\text { TURBULENCE) }\end{array}$ & $\begin{array}{c}\text { SUKKAR AND } \\
\text { CORNELL (WITH NO } \\
\text { TURBULENCE) }\end{array}$ \\
\hline \hline 0 & 1749.81 & 1749.97 \\
\hline 500 & 1772.97 & 1783.44 \\
\hline 1000 & 1796.13 & 1816.91 \\
\hline 1500 & 1819.29 & 1850.37 \\
\hline 2000 & 1842.45 & 1885.56 \\
\hline 2500 & 1865.61 & 1917.31 \\
\hline 3000 & 1888.77 & 1950.77 \\
\hline 3500 & 1911.93 & 1984.24 \\
\hline 4000 & 1935.08 & 2017.7 \\
\hline 4500 & 1958.24 & 2053.96 \\
\hline 5000 & 1981.4 & 2090.66 \\
\hline 5500 & 2004.56 & 2127.36 \\
\hline 6000 & 2028.89 & 2164.07 \\
\hline
\end{tabular}

\begin{tabular}{|c|c|c|}
\hline DEPTH & $\begin{array}{c}\text { THE NEW MODEL } \\
\text { (WITH EFFECT OF } \\
\text { TURBULENCE) }\end{array}$ & $\begin{array}{c}\text { SUKKAR AND } \\
\text { CORNELL (WITH } \\
\text { NO TURBULENCE) }\end{array}$ \\
\hline \hline 1500 & 1819.3 & 1881.28 \\
\hline 2000 & 1842.46 & 1925.04 \\
\hline 2500 & 1865.62 & 1968.8 \\
\hline 3000 & 1888.78 & 2012.55 \\
\hline 3500 & 1911.94 & 2056.31 \\
\hline 4000 & 1935.1 & 2102.53 \\
\hline 4500 & 1958.27 & 2147.67 \\
\hline 5000 & 1981.43 & 2192.82 \\
\hline 5500 & 2004.59 & 2237.96 \\
\hline 6000 & 2028.93 & 2283.11 \\
\hline
\end{tabular}

\section{REFERENCES}

[1] J. Nikuradse, "Stroemungsgesetze in rauhen Rohre", Ver. Dtsch Ing. Forsch. no. 361, 1933.

[2] H. Schlichting. Boundary-Layer Theory. New York: McGraw-Hill, 1979.

[3] C. F. Colebrook, and C.M. White, "Experiments with fluid friction roughened pipes", Proc. R. Soc. Lond., (A) vol. 161, pp. 367-381, 1937.

[4] M.V. Zagarola, "Mean-flow Scaling of Turbulent Pipe flow", Ph.D thesis, Princeton University, USA, 1996.

Table A 3. Table of Bottom-Hole Pressure against Depth for

[5] N.H. Chen, "An explicit equation for friction factor in pipe", Ind. $\mathrm{B}=\mathbf{1 0}$ Eng. Chem. Fundam., vol. 18, No. 3, pp. 296-297, 1979.

[6] K.R Hall, and L. Yarborough, "A new equation of state for z-factor calculations”, Oil. Gas. J., vol. 14, No, 25, pp. 82-92, 1973.

\begin{tabular}{|c|c|c|}
\hline DEPTH & $\begin{array}{c}\text { THE NEW MODEL } \\
\text { (WITH EFFECT OF } \\
\text { TURBULENCE) }\end{array}$ & $\begin{array}{c}\text { SUKKAR AND } \\
\text { CORNELL (WITH } \\
\text { NO TURBULENCE) }\end{array}$ \\
\hline \hline 0 & 1749.81 & 1750 \\
\hline 500 & 1772.97 & 1793.76 \\
\hline 1000 & 1796.13 & 1837.52 \\
\hline
\end{tabular}

[7] L. K. Thomas, R. W. Hankinson, and K. A, Phillips, "Determination of acoustic velocities for natural gas", J. Petrol. Technol., vol. 22, pp. 889-895, 1970.

[8] A. Olufemi, F. A. S. Adesina, and F. Olugbenga, "Predictive tool for bottom-hole pressure in multiphase flowing well", Petroleum Coal, vol. 50, No. 3, pp. 67-73, 2008

[9] C. U. Ikoku. "Natural Gas Production Engineering". Krieger Publishing Company, Malabar Florida, pp. 310-327, 1992.

[10] D. L. Katz, and R. L. Lee, "Natural Gas Engineering-Production and Storage”, McGraw-Hill Publishing Company New York, 1990.

(C) Olufemi et al.; Licensee Bentham Open.

This is an open access article licensed under the terms of the Creative Commons Attribution Non-Commercial License (http://creativecommons.org/licenses/by-nc/3.0/) which permits unrestricted, non-commercial use, distribution and reproduction in any medium, provided the work is properly cited. 